

\title{
An in-depth appraisal of career termination experiences in professional cricket
}

\begin{tabular}{|r|l|}
\hline Journal: & Journal of Sports Sciences \\
\hline Manuscript ID: & RJSP-2014-0079.R2 \\
\hline Manuscript Type: & Original Manuscript \\
\hline Keywords: & retirement, cricket, transitions, antecedents, life satisfaction \\
\hline \multicolumn{2}{|c}{} \\
\hline
\end{tabular}

SCHOLARONE $^{\mathrm{Im}}$
Manuscripts 
1

2

3

4

5

6

7

8

9

10

11

12

13

14

15

16

17

18

19

20

21

22

23

24

25

26

27

28

29

30

31

32

33

34

35

36

37

38

39

40

41

42

43

44

45

46

47

48

49

50

51

52

53

54

55

56

57

58

59

60

1 Running head: Career termination in professional cricket

2

3

4

5

6

7

8 An in-depth appraisal of career termination experiences in professional cricket

9

10

11

12

13

14

15

16

17

18 Date of original submission: 26 January 2014

19 Date of revision: 24 September 2014 


\section{Abstract}

2 This qualitative study explored the career termination experiences of 9 male, retired

3 professional cricketers, between the ages of 28 to $40(M=34, S D=4.65)$. The

4 participants took part in retrospective, semi-structured interviews. Data from the

5 interviews were inductively content analysed within three transition phases of the

6 retirement process: reasons for retirement, factors affecting adaptation, and reactions

7 to retirement. The reasons for retirement were multicausal with the majority of the

8 participants highlighting contractual pressures and a lack of communication as

9 important precursors to retirement. Three main themes accounted for the factors

10 affecting adaptation: a limited pursuit of other interests, developmental experiences

11 and coping strategies. In terms of reactions to retirement, all of the participants

12 reflected negatively on the termination of their career, with a sense of loss and

13 resentment characterising the post-retirement period. The findings illustrated the

14 sport-specific nature of career termination in professional cricket, and added further

15 support to the emerging consensus that the distinction between voluntary and

16 involuntary retirement is, at best, unclear.

17

18 Keywords: retirement, cricket, transitions, antecedents, life satisfaction 


\section{Introduction}

2 Career termination is an inevitable feature of a professional athlete's sporting

3 lifecycle, and is often associated with negative consequences such as identity crises

4 (Brewer, Van Raalte, \& Linder, 1993) and decreased general life satisfaction (Taylor

5 \& Ogilivie, 1994). In the most extreme cases this may lead retired athletes to

6 experience dysfunctional psychopathological reactions such as depression, addictive

7 disorders and the contemplation of suicide (Walker, Thatcher, \& Lavallee, 2007). As

8 such, it is perhaps not surprising that career termination has been afforded increased

9 attention in the sport psychology literature.

10 In an attempt to enhance our understanding of the career termination process a

11 number of models have been proposed in the literature; some describing the

12 variables influencing the quality of the adaptation (e.g., Stambulova, 2003; Taylor \&

13 Ogilivie, 1994) and others the lifecycle of an athletic career (e.g., Wylleman \&

14 Lavallee, 2004). Stambulova (2003) and Taylor and Ogilvie's (1994) models suggest

15 that causal factors or antecedents play a key role in subsequent post-retirement

16 adjustment, with the quality of the transition dependent upon whether the

17 antecedents were voluntary or involuntary (e.g., Webb, Nasco, Riley, \& Headrick,

18 1998). To elaborate, athletes may decide to end their career of their own volition due

19 to a change in priorities such as a desire to start a family (Alison \& Meyer, 1988), to

20 escape financial difficulties (Lavallee, Grove, \& Gordon, 1997) or the politics of the

21 sporting organisation (Werthner \& Orlick, 1986), for work or study commitments

22 (Swain, 1991), the loss of sporting goals (Park, Tod, \& Lavallee, 2012) or decreased

23 enjoyment, motivation and level of competitive performance (Lavallee et al., 1997).

24 Conversely, involuntary causes of retirement include deselection, injury and age

25 (Alfermann, 2000; Taylor \& Ogilvie, 1994). While deselection and injury are clearly 
1 involuntary and, as such, may have negative repercussions for adaptation (cf.

2 Bußman \& Alfermann, 1994; Gardner \& Moore, 2006), age is more complex. As

3 Alfermann and Stambulova (2007) noted, the ageing athlete soon recognises when

4 they cannot operate at the requisite level and are faced with the decision to end their

5 athletic career. From the athlete's perspective, because this decision to retire may to

6 some extent be freely chosen it does not necessarily reflect an involuntary

7 antecedent.

8 While the distinction between voluntary and involuntary retirement remains key

9 to understanding the athlete's response, there is also a growing recognition that the

10 reasons for retirement are often multicausal and part of an extended and dynamic

11 decision-making process (Alfermann \& Stambulova, 2007). Indeed, Park et al.

12 (2012) proposed that athletes experience a series of stages (precontemplation,

13 contemplation, preparation, action), similar to the stages of change in the

14 transtheoretical model (Prochaska \& DiClemente, 1984) when preparing to retire,

15 with readiness to retire key to successful adaptation.

16 Of the factors that influence adaptation to retirement, an athlete's perception of

17 control over the process appears critical (Alfermann, Stambulova, \& Zemaityte,

18 2004). Specifically, athletes who retire on a voluntary basis often report a more

19 healthy transition, for example, exhibiting more positive and less negative emotions

20 (Alfermann, 2000; Alfermann \& Gross, 1998). Other factors affecting adaptation

21 include individual characteristics such as personal and social developmental

22 experiences obtained through peer interactions and exposure to complex

23 environments that help form identity, develop prosocial norms and social capital,

24 which may later impact on the nature of the adjustment to career termination (Taylor

$25 \&$ Ogilvie, 1994). Restricted personal advancement through an all-encompassing 
1 pursuit of athletic goals and the concomitant development of an exclusively athletic

2 identity presents additional adaptational challenges (Lavallee \& Robinson, 2007).

3 Crucially, those with high levels of athletic identity may experience decreased

4 perceptions of control (Webb et al., 1998) and an increased vulnerability to

5 emotional distress (Alfermann \& Gross, 1998), particularly when they have been

6 publicly recognised for their role in sport and define themselves based on their

7 popularity (Ungerleider, 1997). In addition, socioeconomic status, financial

8 dependency on the sport, gender, health, and marital status are also thought to affect

9 the adjustment process (Taylor \& Ogilvie, 1994). Other factors influencing the

10 adaptation process, categorised as resource-related, include coping skills, social

11 support and practical resources, such as pre-retirement planning (e.g., Alfermann, et

12 al., 2004; Park et al., 2012). Taken together, although these different categories of

13 resources are purported to enhance the ability to cope with career termination, we

14 understand less about the availability and effectiveness of some more than others

15 (Alfermann \& Stambulova, 2007). For example, research examining the

16 effectiveness of practical resources, such as planning for retirement and personal

17 development programmes, is sparse. However, where evidence does exist, it

18 suggests that athletes who do plan for retirement are able to adapt to the transition

19 more quickly and report greater life satisfaction (Torregrosa, Boixados, Valiente, \&

20 Cruz, 2004).

21 In terms of the quality of the transition, the most desirable consequence, labelled

22 a "healthy career transition" (Taylor \& Ogilvie, 1994), reflects "successful coping in

23 life" and "success in life" (Alfermann \& Stambulova, 2007). The evidence suggests

24 that healthy transitions are facilitated by the presence of positive reactions such as a

25 sense of freedom, relief and an opportunity for personal growth (e.g., Greendorfer \& 
1 Blinde, 1985; Perna, Ahlgren \& Zaichkowsky, 1999) or the absence of difficulties on

2 retirement (e.g., Sinclair \& Orlick, 1993). In contrast, moderate or extreme

3 repercussions that result in negative consequences, labelled "crisis transitions",

4 reflect the individual's inability to meet the challenges of adaptation to a life post

5 sport (Alfermann et al., 2004; Alfermann \& Stambulova, 2007). These crises may

6 manifest in psychopathological behaviour and social difficulties (Taylor \& Ogilvie,

7 1994), acute depression (Reardon \& Factor, 2010), identity crises (Brewer et al.,

8 1993), difficulties with body image (Kerr \& Dacyshyn, 2000), and occupational

9 problems such as zeteophobia (Lavallee et al., 1997).

10 In the UK, cricket is a sport that has been similarly associated with some of the

11 extreme psychological reactions outlined above. Cricket is a fully professional,

12 international bat and ball sport, contested by two teams of eleven players.

13 Professionally, cricket is played in various formats, ranging from 20 overs per side

14 (Twenty20 cricket), to 50 overs per side (limited overs, or One Day cricket), to a

15 game that can last up to 5 days (first class, or test cricket). In the UK, the sport

16 traditionally involves a 6-month competitive season during the spring and summer

17 months. The remaining 6 months over the autumn and winter comprise the off-

18 season when selected players may travel to the southern hemisphere on tour, while

19 others remain domiciled at home. For elite, international cricketers, the game

20 involves longer spells touring or travelling, with extended periods of time spent in

21 the company of teammates. Due in part to this competitive structure, cricket attracts

22 regular debate over the scale of the demands placed on professional players. Indeed,

23 in recent years, several English cricketers have reported suffering from mental health

24 problems during their career (e.g., Trescothick, 2009). Notwithstanding the

25 pressures of the sport, retirement from cricket can also be problematic, with $34 \%$ of 
1 retired players admitting that they did not feel in control of their lives two years after

2 terminating their career (Professional Cricketers' Association, 2014). Furthermore,

3 those individuals reporting on-going problems with their lives after retirement rated

4 their transition out of professional cricket as "poor". Such problems are purported to

5 lead to further issues of concern, with cricket anecdotally reported to have a high

6 suicide rate amongst its ex-athletes compared to other sports (Frith, 2001). Indeed,

7 according to Frith, cricket is a stressful sport that is compulsive in nature with an

8 inherent uncertainty that has the potential to "damage the soul". Despite this

9 suggestion, there is no empirical data to clarify Frith's claims. Indeed, professional

10 cricket is a sport in which empirical research is scarce. Consequently, the purpose of

11 the present study was to explore the career termination experiences of former

12 professional cricketers in the UK. This focus adds to the existing body of research on

13 multi-sport samples that has failed to address the idiosyncratic nature of career

14 termination in sport. It also addresses criticisms of the quantitative career

15 termination research for being too generic to be practically useful (Greendorfer \&

16 Blinde, 1985), and ineffectual at describing individual's experiences (Blinde \&

17 Strata, 1991; Parker, 1994).

\section{Method}

\section{Participants}

20 A purposive sample of 9 individuals who met the following criteria were invited

21 to participate in the study: (a) participants were male, (b) had represented a county

22 cricket club in England or Wales, and / or the England and Wales national cricket

23 team (at any level), and (c) had retired from professional cricket within a period of 1-

245 years prior to their involvement in the study. Participants' ages ranged from 28 to

2540 years $(M=34, S D=4.65)$, and the mean time elapsed since retirement was 2.3 
1 years $(S D=1.41)$. The participants represented all of the cricketing disciplines ${ }^{1}$

2 (bowler $n=3$, batsman $n=2$, wicketkeeper $n=2$, all-rounder $n=2$ ). Career

3 duration, defined as the date of commencement through to date of termination of the

4 individual's professional cricketing contract, ranged from 3 to 19 years $(M=9, S D=$

5 5.24). Five of the participants had played international cricket for England, and the

6 remaining four played the highest level of domestic professional cricket.

\section{$7 \quad$ Interviews}

8 Semi-structured interviews were conducted using an interview guide designed

9 specifically for this study, based on a review of the research and methodological

10 literature. The guide was organised into five sections. Section 1 outlined the purpose

11 of the study and contained demographic questions about the participant's cricketing

12 career. The first section also reminded participants of their right to withdraw at any

13 time and that information that identified individuals would not be disclosed at any

14 stage of the research process (cf. British Psychological Society, 2010). Based upon a

15 review of the major theoretical models of athletic career transitions (e.g.,

16 Stambulova, 2003; Taylor \& Ogilvie, 1994; Wylleman \& Lavallee, 2004), the next

17 three sections related to three different phases of the career termination process.

18 Section 2 explored the reasons for retirement. The third section addressed the factors

19 that affected the individual's adaptation to life after sport. The penultimate section

20 focused on the participant's reactions to retirement, and the fifth and final section

21 offered participants the opportunity to provide any further information they felt

22 relevant. Probes were used to increase the depth and complexity of participants'

23 responses (Patton, 2002). Questions included: "Can you explain the circumstances

24 behind your retirement from cricket?" and "Can you describe how you felt when

25 your professional cricketing career came to an end?" Feedback from two pilot 
1 interviews enabled the interviewer to refine her interviewing skills and also resulted

2 in a number of minor revisions to the wording and sequencing of questions (Patton,

32002 ) and the addition of further clarification and elaboration probes to obtain a

4 fuller understanding of the participants' perceptions of their experiences.

5 Procedure

$6 \quad$ Following university ethical approval, participants eligible to take part in this

7 study were identified through the first author's contacts at the Professional

8 Cricketer's Association (PCA) and the England and Wales Cricket Board (ECB).

9 Prior to the interview, participants were contacted by telephone and provided with

10 information about the focus of the study and the interviews. Once participants had

11 provided informed consent, a mutually convenient time and location for the

12 interview was arranged (Patton, 2002). The interviews were conducted by the first

13 author, and lasted between 45 and 120 minutes. On completion of each interview,

14 participants were fully debriefed about the purpose of the study. The interviews were

15 recorded in their entirety, transcribed verbatim, and subsequently returned to the

16 participants for member checking (Patton, 2002).

\section{Data Analysis}

18 The interviews generated 75 pages of 1.5 -spaced transcription. The transcripts

19 were read several times in order to gain an in-depth understanding of the data. The

20 three phases of the retirement process that provided the structure of the interview

21 guide formed a deductive framework within which the interview data were

22 inductively content analysed (Patton, 2002). This process of analysis involved

23 identifying and extracting quotations that captured participants' experiences firstly

24 on a case-by-case basis and subsequently across cases (Miles \& Huberman, 1994). 
1 Quotations with similar meaning were grouped into lower-order categories and the

2 categories subsequently clustered together into higher-order themes (Patton, 2002).

3 A number of procedures were employed to enhance the trustworthiness of the

4 data. Member checking helped to ensure the adequacy and accuracy of the

5 information, and protect against potential misinterpretations and researcher

6 subjectivity (Lincoln \& Guba, 1985). All of the participants confirmed the accuracy

7 and adequacy of the data. Additionally, at every stage of analysis, the first and

8 second authors engaged in coding consistency checks where validity was established

9 when the same conclusions were drawn from the data. Additionally, peer debriefing

10 was employed with the second author at each stage of the study to protect against

11 researcher bias; the second author fulfilled a protagonist role (Lincoln \& Guba,

12 1985).

$13 \quad$ Results and Discussion

14 The main aim of the present study was to explore the career termination

15 experiences of retired professional cricketers. The findings are considered within the

16 deductive framework provided by the career termination literature: reasons for

17 retirement, factors affecting adaptation and reactions to retirement. Each of these are

18 described and explained below using the lower order categories and higher order

19 themes that emerged from the inductive analysis of the data. A summary of the

20 findings is depicted in Table 1.

21

22

**** TABLE 1 NEAR HERE****

23

24 Reasons for retirement 
1 The participants' reasons for retirement were characterised by four categories:

2 reluctant retirees, contractual pressures, lack of communication and sport

3 devaluation, which formed one overall higher-order theme, multicausality. As such

4 our results support the emerging consensus that the distinction between voluntary

5 and involuntary career terminations fails to capture the full complexity of athletes'

6 reasons for retirement (cf. Kerr \& Dacyshyn, 2000; Koukouris, 1994; Park et al.,

7 2012).

8 The category reluctant retirees reflected participants taking the decision to retire

9 from professional cricket themselves, but not perceiving this decision as being a

10 truly free choice. These participants suggested that a combination of factors meant

11 that they perceived retirement to be the only option available to them in order to

12 escape the pressures associated with attempting to prolong their careers (cf. Kerr \&

13 Dacyshyn, 2000). The second category, contractual pressures, reflected the perceived

14 threat of not having a professional contract renewed and the financial and

15 occupational uncertainty that accompanies this situation (cf. Lavallee et al., 1997;

16 Swain, 1991). All of the participants who perceived their retirement as being

17 voluntary $(n=3)$ or who were classed as reluctant retirees $(n=5)$ described the

18 “overwhelming psychological bearing" that contractual pressures had on their

19 decision to retire. They suggested that retirement for contractual reasons was seen as

20 an "exit strategy" from the "emotional instability" (Participant D) associated with

21 playing continuously for the one-year contracts that are commonplace in

22 professional cricket in England and Wales. One participant suggested;

23 The stress was too much. I had no idea whether I'd get another contract; nobody

24 was giving me any information. I was living on the edge; I had to get out ... get 
1

2

3 As Alfermann and Stambulova (2007) noted, studies with professional athletes are

4 rare and this study highlights the role that the pressure of securing a professional

5 contract plays in retirement from professional cricket.

6

7

8 This lack of communication exacerbated the difficulties experienced by the

9 participants, especially during contract renewal periods. Individuals reported feeling

10

11

12

13

14

In conjunction with this contractual uncertainty, all of the participants reported

that there was often a lack of communication from the club regarding their future.

as if they were continuously second-guessing the club's decision to renew their

contracts or selection for a squad. In the absence of adequate information, the

participants interpreted the lack of communication and demotion to the reserve team

as cricket clubs "favouring" younger players (Participant I). One participant referred

to being made to feel "past your sell-by-date" (Participant C). Another described his

perception of the commercial impact of retaining older players:

The way the club was going, they took an economic decision. They would have rather paid a couple of juniors than an older guy who's only going to play the longer format of the game. They had all these kids coming through; it was just the law of economics really. (Participant F)

In addition, players reported that they often felt "isolated" from their teammates and "commodified" when it was identified that their cricketing career was coming to an end (Participant I). Clubs were reported to "wash their hands" of the player:

When I was dropped to the second team, the communication straight away was gone. One minute you're in the team, the next you're not. There was no communication ... I'll try not to sound too bitter about this ... I got a text 
1

2

3

4

5

6

7

8

message saying "we will not renew your contract" . . It could have been so much better for me if I'd known. It's sort of ripped away from you and within the space of five minutes you go from being a cricketer to being unemployed. (Participant C)

This category supports previous research that has identified poor communication within teams as an organisational stressor (e.g., Fletcher \& Hanton, 2003; Woodman \& Hardy, 2001).

The final category relating to the reasons for retirement was sport devaluation, which emerged from the physiological and psychological impact of aging on the decision to retire. The physiological impact of aging was linked to the threat of deselection, difficulties in commanding a regular first team place and the perception that clubs favoured younger players. Participant D spoke of how physiological changes influenced his decision to retire; “. . . I wasn't poor but I probably wasn't as good as the standards I'd set in the past 5 years". The psychological aspects of aging were primarily linked to a loss of motivation. Participant I spoke of how his "motivation disappeared" and that he'd "totally lost his drive". Participant G explained:

I'd had enough, I used to turn up at the [cricket] ground and think ... God I play too much ... I'm sick of this bloody game. I was completely and utterly sick of cricket, my motivational style somehow changed one day. I fell out of love with the game. I don't know why ... I certainly didn't want to.

The intensity of Participant G's response is consistent with the construct of sport devaluation, a symptom of burnout, and a feature that may further complicate career termination and adaptation to retirement; however, only three participants reported this type of reaction. The multicausal nature of the decision to retire also appeared to 
1 result in symptoms consistent with emotional exhaustion, as described in the burnout

2 literature (cf. Cresswell \& Eklund, 2006). Participants who retired voluntarily or

3 were classed as reluctant retirees reported that a combination of markers (age, threat

4 of deselection, and a lack of communication) led them to pre-empt the possibility

5 that the cricket club may not renew their contract: "I wasn't getting any better, it was

6 so demoralising. I thought I'd pre-empt someone else's decision and hang my boots

7 up, so to speak" (Participant E). In summary, the multicausal nature of the reasons

8 for the participants' retirement confirms the observations of Alfermann and

9 Stambulova (2007) and Lavallee et al. (1997) that a combination of factors

10 influences retirement from sport, while also contributing new insight into the nature

11 of these within the sport of cricket.

12 Factors affecting adaptation

13 Three themes accounted for the factors that affected participants' adaptation:

14 limited pursuit of other interests, developmental experiences and coping strategies.

15 Limited pursuit of other interests comprised two categories: lack of control

16 throughout career and lack of opportunity for developmental experiences. The

17 participants highlighted the negative effect that their perceived lack of control

18 throughout their cricketing careers had on the subsequent adjustment to retirement

19 (Kerr \& Dacyshyn, 2000; Lavallee \& Robinson, 2007). Six of the participants

20 explained that not having any "responsibility or control" over their lives while

21 playing cricket and conforming to a "structured and regimented existence" presented

22 them with "difficulties envisaging themselves outside of this environment"

23 (Participant C). Participant D expanded on this issue, commenting that “...

24 problems come from where you've got guys who are used to having everything done

25 for them ... guys can't stand on their own two feet, that's where they've got 
1 problems and will struggle". However, this perceived lack of control during their

2 career had additional implications for the individuals' developmental experiences.

3 Participants explained how they felt that the cricketing environment limited their

4 pursuit of other interests, thereby restricting opportunities for their personal and

5 professional development outside of the sport; which in-turn detrimentally affected

6 their adaptation to retirement:

7 It's really tricky to develop an enthusiasm for anything other than cricket. They

8 [coaches] think you're not giving your full 100\% to your game. I wish I had

9 something outside of cricket, I would have found it easier to cut myself off.

10 (Participant J)

11 Under the rubric of developmental experiences three categories emerged:

12 education, using the off-season more effectively and ineffective personal

13 development programmes. The role that education played in the adaptation process

14 was highlighted by participants as being a potential "protecting factor" (Participant

15 F), a "cushion in the background" and something that gave the individuals

16 "empowerment" and "the potential" to adapt (Participant H). Participants

17 emphasised the importance of pursuing their education before, or during their

18 cricketing career, rather than approaching or following retirement. Previous research

19 has suggested that acquiring academic qualifications prior to retirement may enhance

20 post-athletic life satisfaction and self-esteem (Kleiber \& Malik, 1989), providing the

21 basis for the development of non-athletic identities and skills transferable to other

22 domains relevant to a second career (Price, Morrison, \& Arnold, 2010).

23 In summary, the majority of the participants in the present study identified the

24 lack of opportunity to explore developmental experiences such as education, as

25 limiting their ability to adapt to retirement. Participants felt that they should have 
1 made more of the off-season in cricket to explore post-career employment

2 opportunities, which they saw as a form of pre-retirement planning. The competitive

3 season in professional cricket can be up to 6 months long, unless players are engaged

4 at international level, where the season can occupy 10 months of the year. Indeed,

5 the break from the competitive schedule (September to April in the UK) was

6 described by participants as "notoriously under-utilised", despite providing an ideal

7 window in which the individuals could engage in, for example, practical work

8 experience. The findings of the present study support the suggestion that rehearsal

9 opportunity might assist in the quality of the transition process (Goodman,

10 Schlossberg, \& Anderson, 2006).

11 Although a personal development programme jointly administered by the PCA

12 and the ECB offering a number of services (e.g., training, mentoring, work

13 placements) is available to assist all professional cricketers in their preparation for

14 life after the game, it appears that there is a reluctance to participate in the

15 programme, perhaps in part because of doubts about its effectiveness. Participants in

16 the present study reported these services to be "ineffective" and "undirected"

17 (Participant B) with "little incentive or promotion of the services on offer by the

18 clubs" (Participant J). The negative perception of the programme on offer reinforces

19 the findings of earlier studies that have also revealed player's unwillingness to

20 participate in such schemes and plan for their post athletic career (Gorely, Lavallee,

21 Bruce, \& Teale, 2001; Petitpas \& Champagne, 2000). However, the participants in

22 the present study highlighted additional concerns regarding the appropriateness of

23 the programme content and the way the county cricket clubs perceive these services.

24 The third theme, coping strategies, comprised the categories of problem-focused

25 coping, avoidance-focused coping and social support. Analysis of the transcripts 
1 revealed that participants used problem- and avoidance-focused strategies to help

2 deal with the issues that confronted them on their retirement from sport. One

3 participant (F) illustrated the problem-focused coping strategies he employed:

$4 \quad$ I was just very conscious of moving on and finding something else that I could

5 try and be good at. I kind of immediately enrolled on a course, got involved with

6 a football team, and I just ... I wanted to avoid developing dodgy habits at all

$7 \quad$ costs and focus on things functional toward my future.

8 In contrast, Participant $\mathrm{C}$ illustrated the use of avoidance coping strategies:

9 I thought I knew what was coming, but as it ended up, I hadn't got a clue. And

10 you know, I was stewing about it, so I tried to stop thinking about it. I know it

11 sounds like I'm storing a lot of problems in later life or something ... I don't

12 know ...

13 There was no evidence of any of the participants having employed emotion-focused

14 coping strategies, thereby failing to take advantage of the potential benefits that

15 could be conferred by engaging in this coping strategy (Alfermann \& Stambulova,

16 2007).

17 The final category in the coping strategies theme, social support, has been

18 identified as playing a crucial role in the transition of retiring athletes (Petitpas \&

19 Champagne, 2000). Although participants' primary social support was derived from

20 their athletic involvement (cf. Coakley, 1983; Rosenfeld, Richman, \& Hardy, 1989),

21 support was not always readily available during the transition process. The

22 participants expressed regret that they were unable to talk to teammates about the

23 transition; with over half suggesting that more appropriate social support during the

24 build-up to the transition would have facilitated both the transition and their

25 adaptation to life after professional cricket. Participant $\mathrm{C}$ recalled: 
$1 \quad$ You're like a wounded animal that gets left alone. I think definitely people ...

2 cricketers ... don't want to talk about the end of their careers and if you're in a

3 position where it looks like you're coming to the end of yours . . . men aren't

4 very good at talking anyway so they don't want to talk about your problems, but

5 they also don't want to talk about a problem that's going to affect the

6 atmosphere. So you do get yourself into a situation, which is like being in a

7 vacuum where nobody wants to talk about what's happening, but they all know

$8 \quad$ it is happening.

9 Parker (1994) identified similar issues, suggesting that a reluctance to discuss

10 impending retirement could affect the psychological well being of individuals by

11 creating the potential for residual emotions that have not been addressed sufficiently

12 in the transitional process. Participants describing the loss of their social support

13 network also highlighted further difficulties following retirement. Participant $\mathrm{H}$

14 noted:

15 Well I missed out on the camaraderie when I wasn't involved . . . some friends,

16 some of them, some team mates literally dropped me overnight because I was no

17 longer contributing to their social circle which is . . I mean I spotted straight

18 away, and dealt with that. It was a bit of an eye opener.

19 Sinclair and Orlick (1993) also found that athletes in their study frequently reported

20 missing the social aspects of their sport. In addition, participants' restricted social

21 identity and the absence of alternative sources of social support may have

22 contributed to the feelings of isolation felt following their retirement (Alfermann,

23 1995; Schmid \& Schilling, 1997). In summary, the participants described how a loss

24 of personal control, the potential for disempowerment during a professional cricket 
1 career, and the lack of social support during the transition might have exacerbated

2 difficulties in adapting to life after cricket.

\section{Reactions to retirement}

4 Three themes accounted for participants' reactions to retirement: loss, negative

5 emotions and occupational problems. The theme of loss comprised three categories:

6 social losses, personal losses and a loss of physical capacity. Participants described

7 these losses regardless of whether they had reported retiring voluntarily or

8 involuntarily. For example, when describing the enduring effects of retirement

9 Participant E reported:

10 I still dream about it [cricketing career]. Walking out to bat. Being on the back

11 pages [of newspapers] the next day. The camaraderie ... my friends . . who I

12 was ... That's all gone now and I'm not sure I was really ready to let it go.

13 The theme negative emotions also comprised three categories, negative

14 reflection, void and bitterness. When asked to comment on the quality of their

15 transition, participants explained how they reflected on the experience with

16 "negativity and regret" (Participant E). In addition, some participants criticized the

17 manner in which they were treated by their organizations during the transition.

18 Participant B described how this treatment "cast a cloud over my [cricketing] career,

19 meaning I was isolated from my environment...everything I knew.” Furthermore, one

20 participant whose elite career spanned 19 years described his transition as:

21 Like the break-up of a marriage. It is so involving, and it's so all encompassing.

22 And suddenly ... there's nothing. . . I had one love in life and it was cricket ...

23 and I guess when you realise you can't play it all the time anymore it is a very

24 sad day, and I now wonder what all the hard work was for. (Participant A) 
1 Following retirement Participant I reported experiencing a void that he continues to

2 struggle to fill:

3 When it was coming to an end [cricketing career] I was asking myself "what if

$4 \quad$ this is a good as it gets?" Cricket, I mean. Then it [retirement] comes, and

5 there's a gap. A void. Yes, Ok, I am working, but it's no substitute, I didn't . . .

6 and still don't know how to fill it.

7 Participants also reported experiencing negativity and a sense of bitterness for

8 up to five years after career termination, with no differences among those citing

9 voluntary or involuntary retirement. In relation to the reaction to retirement,

10 previous research has suggested elite athletes experience a "brief" and "occasional"

11 sense of loss on retirement (Curtis \& Ennis, 1988). However, our findings suggest

12 that this reaction may be more enduring in the professional cricketing population.

13 The final theme, occupational problems, comprised two categories; lack of

14 career direction and similar professions. The participants' accounts suggested that

15 they faced occupational problems that manifested themselves in the form of a

16 continued lack of career direction $(n=5)$, despite the provision of the personal

17 development programme. This was commonplace among the participants who had

18 ended their careers voluntarily. For example, Participant I claimed:

19 I'm still in a bit of a quandary as to what I want to do really. You know, I've got

20 some passions...sport for example. I just want to be successful in what I do, and

21 I just want to emulate my cricketing career.... You know, I'm a creature of habit

22 I will pursue a goal and everything will stop in order for me to drive forward.

23 But I don't know how successful I can be outside of cricket. I just don't know

24 what to do. 
1 The majority of participants suggested that moving into similar professions on

2 the cessation of their cricket career may have protected them against the adverse

3 psychological consequences associated with retirement: "I was petrified of working

4 in an office. If I couldn't play cricket, I wanted to move to something with the same

5 challenges" (Participant H). Professions that shared preferred characteristics with a

6 cricketing career such as competitiveness, physicality, travel, working in a team and

7 performance related assessment as being desirable features of their post-cricket

8 occupation were cited.

9 In terms of the quality of the transition, research suggests that athletes

10 experience either a "healthy career transition" or a "retirement crisis" (e.g., Taylor \&

11 Ogilvie, 1994). Alfermann and Stambulova (2007) defined a "healthy career

12 transition" as consisting of two elements; successful coping with the career

13 termination process and success in life. In summary, the present study failed to find

14 any support for either aspect of a healthy career transition, even among participants

15 who reported retiring voluntarily. That is to say, all of the participants in this study

16 reported some difficulty adapting to life after cricket; however, despite these

17 difficulties there was no evidence to suggest the presence of any serious retirement

18 crises in the form of substance abuse or psychopathology. Instead, the present study

19 suggests that retiring athletes' experiences may fall somewhere along a continuum of

20 retirement crises and unproblematic, straightforward adaptation (e.g., Alfermann et

21 al., 2004; Lally, 2007; Sinclair \& Orlick, 1993).

22 The present study had a number of strengths and limitations. First, the study

23 involved the retrospective recall of a small sport-specific, purposeful sample of ex-

24 professional cricketers in England and Wales. In some cases participants were

25 expected to account for events up to six years prior to interview, and potentially the 
1 data may have been subject to response or retrospective recall bias. However, we

2 contend that the retrospective nature of our study afforded the participants the

3 opportunity to reflect on their experiences in ways that could not have been readily

4 accessed by other approaches. The present study is also gender and culture specific;

5 as such, the findings are limited to the male professional game in England and

6 Wales.

7 Research conducted with professional cricketers is rare. This study has

8 highlighted the role that commercial and contractual pressures play in the transition

9 process. Future research should seek to gain a clearer understanding of how such

10 pressures impact athletes and their subsequent transition. Similarly, the role of

11 burnout as a potential antecedent to retirement from elite sport should be

12 investigated further, especially as it has previously been found to correlate strongly

13 with affective disorders (Cresswell \& Eklund, 2007; Peluso \& deAndrade, 2005).

14 Finally, it is recommended that the outcome of the transition process be examined, as

15 it appears too simplistic to suggest that individuals experience either a healthy

16 transition or a retirement crisis at the end of their careers.

17 The findings here should help enable sport psychologists to identify cricketers at

18 risk of adaptation problems particularly in relation to the following risk criteria:

19 contractual pressures, little educational preparation, and few interests outside of

20 cricket. The absence of any emotion-focused strategies also highlights a key area of

21 importance for sport psychologists, with a clear priority being increasing awareness

22 of the importance of emotional coping. Sport psychologists therefore, need to be

23 prepared to teach cricketers to regulate emotional responses, to seek out emotional

24 social support and to modify cognitive efforts to re-appraise stressors. There are also

25 a number of implications for cricket's governing and professional bodies. First, the 
1 proposal that the devaluation of the individual's autonomy during a professional

2 cricketing career may delay adaptation to a post-sport life should be addressed.

3 Issues relating to personal autonomy and control are linked to the structure of an

4 organization and practitioners need to be able to influence change at an

5 organizational level as this social context appears to be just as significant as

6 individual difference factors. Moreover, as our results call into question the

7 effectiveness of structured career transitions programmes, current provision should

8 be reviewed. The participants' accounts provide an insight into how future pre-

9 retirement planning interventions may be better directed to counteract occupational

10 problems and the reported lack of career direction. Communication between players

11 approaching a transition out of the game and coaches and administrators should be

12 regular, open and honest to ensure that players' expectations are managed with

13 regard to future selection and contract renewal.

14 In conclusion, this study is the first to examine the retirement experiences of

15 elite cricketers. The in-depth examination of the issues experienced by the

16 participants reinforced the suggestion that retirement from sport is influenced by a

17 range of factors. Consequently, readiness to retire may be a more appropriate driver

18 of the quality of adjustment to life after sport than the commonly held voluntary

19 versus involuntary retirement dichotomy. As noted, future research should focus

20 upon role of contractual and commercial pressures and burnout as possible

21 antecedents as well as provide a more detailed examination of the outcomes of the

22 retirement process. Further investigation along these lines of enquiry will help build

23 a more robust body of empirical evidence enabling practitioners to better prepare

24 athletes for retirement from their sport. 
1

2 Alfermann, D. (1995). Career transitions of elite athletes: Dropout and

3 retirement. In R. Vanfraechem-Raway \& Y. Van den Auweele (Eds.), Proceedings

4 of the $9^{\text {th }}$ European Congress on Sport Psychology (pp. 828-833). Brussels:

5 European Federation of Sport Psychology.

6 Alfermann, D. (2000). Causes and consequences of sport career termination. In

7 D. Lavallee, \& P. Wylleman (Eds.), Career transitions in sport: International

8 perspectives (pp. 45-58). Morgantown, WV: Fitness Information Technology.

$9 \quad$ Alfermann, D., \& Gross, A. (1998). How elite athletes perceive and cope with

10 career termination. Lestungssport, 28, 45-48.

11 Alfermann, D., \& Stambulova, N. (2007). Career transitions and career

12 termination. In G. Tenebaum \& R. C. Eklund (Eds.). Handbook of sport psychology

$13 \quad\left(3^{\text {rd }}\right.$ ed., pp. 712-736). New York: Wiley.

14 Alfermann, D., Stambulova, N., \& Zemaityte, A. (2004). Reactions to sport

15 career termination: A cross-national comparison of German, Lithuanian, and Russian

16 athletes. Psychology of Sport and Exercise, 5, 61-75. doi:10.1016/S1469-

17 0292(02)00050-X

18 Alison, M. T., \& Meyer, C. (1988). Career problems and retirement amongst

19 elite athletes: the female tennis professional. Sociology of Sport Journal, 5(3), 212-

20222.

21 Blinde, E. M., \& Strata, T. M. (1992). The 'sport career death' of college

22 athletes: Involuntary and unanticipated sport exits. Journal of Sport Behavior, 15, 3-

2320. 
1 Brewer, B. W., Van Raalte, J. L., \& Linder, D. E. (1993). Athletic identity:

2 Hercules' muscles or Achilles Heel? International Journal of Sport Psychology, $3 \quad 24(2), 237-254$.

4 Bußmann, G., \& Alfermann, D. (1994). Drop-out and the female athlete. In D.

5 Hackfort (Ed.), Psycho-social issues and interventions in elite sport (pp. 90-128).

6 Frankfurt, Germany: Lang.

7 British Psychological Society (2010). Code of human research ethics. Leicester, 8 UK: British Psychological Society.

9 Coakley, J. J. (1983). Leaving competitive sport: Retirement or rebirth. Quest, $10 \quad 35,1-11$.

11 Cresswell, S. L., \& Eklund, R. C. (2006). The nature of player burnout in rugby:

12 Key characteristics and attributions. Journal of Applied Sport Psychology, 18(3), 13 219-239. doi: 10.1080/10413200600830299

14 Curtis, J., \& Ennis, R. (1988). Negative consequences of leaving competitive 15 sport? Comparative findings for former elite-level hockey players. Sociology of 16 Sport Journal, 5(2), 87-106.

17 Fletcher, D., \& Hanton, S. (2003). Sources of organizational stress in elite sports 18 performers. The Sport Psychologist, 17(2), 175-195.

19 Frith, D. (2001). Silence of the heart: Cricket suicides. London: Mainstream 20 Publishing.

21 Gardner, F. L., \& Moore, Z. E. (2006). Clinical sport psychology. Champaign, 22 IL: Human Kinetics.

23 Goodman, J., Schlossberg, N. K., \& Anderson, M. L. (2006). Counseling adults 24 in transition (3rd ed.). New York: Springer Publishing Company. 
1 Gorley, T., Lavallee, D., Bruce, D., Teale, B., \& Lavallee, R. (2001). A

2 sampling of perceptions of potential users of the Australian Athlete Career and

3 Education Programme. Academic Athletic Journal, 15, 11-21.

4 Greendorfer, S., \& Blinde, E. (1985). "Retirement” from intercollegiate sport:

5 Theoretical and empirical considerations. Sociology of Sport Journal, 2(2), 101-110.

6 Kerr, G., \& Dacyshyn, A. (2000). The retirement experiences of elite, female

7 gymnasts. Journal of Applied Sport Psychology, 12(2), 115-133.

8 doi:10.1080/10413200008404218

9 Kleiber, D. A., \& Malik, P. B. (1989). Educational involvement of college

10 athletes and subsequent well-being in early adulthood. Journal of Sport Behavior,

$11 \quad 12(4), 203-211$.

12 Koukouris, K. (1994). Constructed case studies: Athletes' perspectives of

13 disengaging from organized competitive sport. Sociology of Sport Journal, 11(2),

$14 \quad 114-139$.

15 Lally, P. (2007). Identity and athletic retirement: A prospective study.

16 Psychology of Sport and Exercise, 8(1), 85-99.

17 doi:10.1016/j.psychsport.2006.03.003

18 Lavallee, D., Grove, J. R., \& Gordon, S. (1997). The causes of career

19 termination from sport and their relationship to post-retirement adjustment among

20 elite-amateur athletes in Australia. Australian Psychologist, 32, 131-135.

21 Lavallee, D., \& Robinson, H. (2007). In pursuit of an identity: A qualitative

22 exploration of retirement from women's artistic gymnastics. Psychology of Sport and

23 Exercise, 8(1), 119-141. doi:10.1016/j.psychsport.2006.05.003

24 Lincoln, Y. S., \& Guba, E. (1987). Ethics: The failure of positivist science.

25 Review of Higher Education, 12, 221-240. 
1

2

3

4 decision-making process based on the transtheoretical model. Psychology of Sport

5 and Exercise, 13(4), 444-453. doi:10.1016/j.psychsport.2012.02.003

6 Parker, K. B. (1994). "Has-beens" and "wanna-bes": Transition experiences of

7 former major college football players. The Sport Psychologist, 8(3), 287-304.

$8 \quad$ Patton, M. Q. (2002). Qualitative research and evaluation methods (3rd ed.).

9 Thousand Oaks, CA: Sage.

10 Peluso, M., \& deAndrade, L. H. (2005). Physical activity and mental health: The 11 association between exercise and mood. Clinics, 60(1), $61-70$.

12 Petitpas, A. J., \& Champagne, D. E. (2000). Sport and social competence. In S.

13 J. Danish \& T. P. Gullotta (Eds.), Developing competent youth and strong

14 communities through after-school programming (pp. 115-137). Washington DC:

15 CWLA Press.

16 Perna, F. M., Ahlgren, R. L. \& Zaichkowsky, L. (1999). The influence of career

17 planning, race, and athletic injury on life satisfaction among recently retired

18 collegiate male athletes. The Sport Psychologist, 13(2), 144-157.

19 Price, N., Morrison, N., \& Arnold, S. (2010). Life out of the limelight:

20 Understanding the non-sporting pursuits of elite athletes. International Journal of

21 Sport and Society, 1(3), 69-79.

22 Professional Cricketers' Association (2014, September 12). PPF Announces the

23 Results of a Major Cross-Sport Study into the Physical, Mental and Financial Well-

24 being of Retired Sportspeople. Retrieved from: http://www.thepca.co.uk/ppf- 
1 announces-the-results-of-a-major-cross-sport-study-into-the-physical-mental-and-

2 financial.html

3 Prochaska, J. O. and DiClemente, C. C. (1984). The Transtheoretical Approach:

4 Crossing traditional boundaries of therapy. Homewood, IL: Dow Jones Irwin.

5 Reardon, C. L., \& Factor, R. M. (2010). Sport psychiatry: A systematic review

6 of diagnosis and medical treatment of mental illness in athletes. Sports Medicine,

7 40(11), 961-980. doi:10.2165/11536580-000000000-00000

8 Rosenfeld, L. B., Richman, J. M., \& Hardy, C. J. (1989). Examining social

9 support networks among athletes: Description and relationship to stress. The Sport

10 Psychologist, 3(1), 23-33.

11 Schmid, J., \& Schilling, G. (1997). Identity conflicts during and after retirement

12 from top-level sports. In R. Lidor, \& M. Bar-Eli (Eds.), IX World Congress of Sport

13 Psychology: Proceedings (Part II, pp. 608-610). Netanya, Israel: International

14 Society of Sport Psychology.

15 Sinclair, D. A., \& Orlick, T. (1993). Positive transitions from high-performance

16 sport. The Sport Psychologist, 7(2), 138-150.

17 Stambulova, N. (2003). Symptoms of a crisis-transition: A grounded theory

18 study. In N. Hassmén (Ed.), SIPF Yearbook 2003 (pp. 97-109). Örebro: Örebro

19 University Press

20 Swain, D. A. (1991). Withdrawal from sport and Schlossberg's model of

21 transitions. Sociology of Sport Journal, 8(2), 152-160.

22 Taylor, J., \& Ogilvie, B. (1994). A conceptual model of adaptation to retirement

23 among athletes. Journal of Applied Sport Psychology, 6(1), 1-20. 
1 Torregrosa, M., Boixados, M., Valiente, L., Cruz, L. (2004). Elite athletes'

2 image of retirement: The way to relocation in sport. Psychology of Sport and

3 Exercise, 5, 35-44.

4 Trescothick, M. (2009). Coming back to me: The Autobiography. London:

5 Harper Sport.

$6 \quad$ Ungerleider, S. (1997). Olympic athletes' transition from sport to workplace.

7 Perceptual and Motor Skills, 84(3), 1287-1295. doi:10.2466/pms.1997.84.3c.1287

8 Walker, N., Thatcher, J., \& Lavallee, D. (2007). Psychological responses to

9 injury in competitive sport: A critical review. Journal of the Royal Society for the

10 Promotion of Health, 127(4), 174 - 180. doi:10.1177/1466424007079494

11 Webb, W. M., Nasco, S. A., Riley, S., \& Headrick, B. (1998). Athletic identity

12 and reactions to retirement from sport. Journal of Sport Behavior, 21(3), 338-362.

13 Werthner, P., \& Orlick, T. (1986). Retirement experiences of successful

14 Olympic athletes. International Journal of Sport Psychology, 17, 337-363.

15 Woodman, T., \& Hardy, L. (2001). A case study of organisational stress in elite 16 sport. Journal of Applied Sport Psychology, 13(2), 207-238.

17 doi:10.1080/104132001753149892

18 Wylleman, P., \& Lavallee, D. (2004). A developmental perspective on 19 transitions faced by athletes. In M. Weiss (Ed.), Developmental sport and exercise 20 psychology: A lifespan perspective (pp. 507-527). Morgantown, WV: Fitness

21 Information Technology. 


\section{Table 1. Summary of themes and categories}

\section{Categories $^{2}$}

Reluctant retirees (5)

Contractual pressures (8)

Lack of communication (8)

Sport devaluation (3)

Lack of control throughout career (6)

Lack of opportunity for developmental

experiences (8)

Education (7)

Using the off-season more effectively (5)

Ineffective personal development

programme (5)

Problem-focused coping (4)

Avoidance-focused coping (5)

Social support (7)

Social losses (5)

Personal \& social identity losses (6)

Loss of physical capacity (4)

Negative reflection (9)

Void (6)

Bitterness (6)

Lack of direction (5)

Similar professions (5)

\section{Themes}

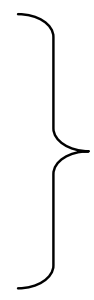

Multicausality

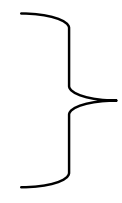

Reasons for retirement

Limiting the pursuit

of other interests

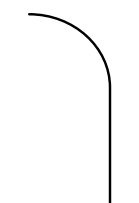

